\title{
Ultrasonic Inspection of AA6013 Laser Welded Joints
}

\author{
Adriano Passini ${ }^{\mathrm{a}}$, Aline Capella de Oliveira ${ }^{\mathrm{b}}$, Rudimar Riva ${ }^{\mathrm{b}}$, \\ Dilermando Nagle Travessac*, Kátia Regina Cardoso ${ }^{\mathrm{c}}$ \\ ${ }^{a}$ Empresa Brasileira de Aeronáutica S.A. - Embraer, \\ Av. Brigadeiro Faria Lima 2170, CEP 12227-901, São José dos Campos, SP, Brazil \\ ${ }^{b}$ Divisão de Fotônica, Instituto de Estudos Avançados - IEAv, \\ CEP 12228-001, São José dos Campos, SP, Brazil \\ ${ }^{c}$ Departamento de Ciência e Tecnologia, Universidade Federal de São Paulo - UNIFESP, \\ Rua Talim 330, CEP 12231-380, São José dos Campos, SP, Brazil
}

Received: May 11, 2011; Revised: July 15, 2011

\begin{abstract}
Interest in laser beam welding for aerospace applications is continuously growing, mainly for aluminum alloys. The joints quality is usually assessed by non-destructive inspection (NDI). In this work, bead on plate laser welds on $1.6 \mathrm{~mm}$ thick AA6013 alloy sheets, using a $2 \mathrm{~kW}$ Yb-fiber laser were obtained and inspected by pulse/echo ultrasonic phased-array technique. Good and poor quality welds were inspected in order to verify the limits of inspection, comparing also to X-ray radiography and metallographic inspections. The results showed that ultrasonic phased array technique was able to identify the presence of grouped porosity, through the attenuation of the amplitude of the echo signal. This attenuation is attributed to the scattering of the waves caused by micro pores, with individual size below the resolution limit of the equipment, but when grouped, can cause a perceptive effect on the reflection spectra.
\end{abstract}

Keywords: ultrasonic inspection, pulselecho phased array, laser welding, aluminum alloy

\section{Introduction}

Laser beam welding (LBW) is an attractive joining process for aluminum structures, due to its high production rate, associated with high quality welds. The high concentrated energy (around $10^{6} \mathrm{~W} \cdot \mathrm{cm}^{-2}$ ) in a precision controlled spot enables welding in key-hole mode, at welding speeds up to $10 \mathrm{~m} / \mathrm{min}$ in thin sheets, resulting in a very narrow heat affected zone. Those characteristics are attractive for both automotive and aerospace industries. For aircraft manufacturing, for example, the weldable $\mathrm{Al}-\mathrm{Mg}-\mathrm{Si}-\mathrm{Cu}$ alloy has been used for fuselage applications substituting the conventional riveted structure ${ }^{1-3}$. However, the use of welded structures on airframes demands a qualified and robust welding process, including a reliable defect control system, based on NDI techniques. Further, the inspection technique should be performed rapidly and preferably during the welding (in process inspection), to not become the bottleneck of the process.

Radiographic inspection is widely used for weld inspection. Based on X-Ray or neutron absorption, it strongly depends on the mass of the material and is precise in detecting volumetric defects related to both extra and missing material ${ }^{4}$. It is less effective in detecting planar defects like cracks that are usually the most critical type of defect in welds, unless it is appropriately oriented to the radiation source. This implies in inspection in more than one direction. Further, radiographic inspection is a high timing and cost consuming process.

Ultrasonic waves are usually scattered by both planar and volumetric defects in solids, and through appropriated procedures, it can give precise information about defect position and size ${ }^{4}$. Additional advantages of the ultrasonic method over the radiographic inspection are the low-cost, high productivity and lack of radiation.
The use of advanced multi-piezoelectric probes (phased-array) still improves de flexibility of the process, enabling a faster scanning and allowing the inspection in several angles simultaneously. Further, an electronic focus enables different wave configurations and scanning modes ${ }^{5}$. However, the transducer coupling, a critical step in such inspection, leads to some specific cares regarding to the surface roughness and the use of coupling substances, slowing the process and imposing geometric restrictions. These difficulties have been overcome by new techniques like non contact air-coupled transducers $^{6,7}$ and laser-ultrasonic detection techniques ${ }^{8,9}$. Further, ultrasonic inspection usually fails in detecting superficial and subsuperficial defects, and in these cases Eddy-current inspection is more appropriate.

Most of the recent advances in NDI for welds are related to arc welding of pipeline steels or resistance spot welding in steel sheets for automotive industry. These advances are related to both new inspection ${ }^{8,10-12}$ and new signal processing ${ }^{13-15}$ techniques.

The development of fast and reliable procedures for welds inspection is an important step to increase the use of the LBW process, mainly in the aerospace industry. Other important steps include the development of a robust welding process, integrated to a quality system, qualification and certification of inspectors and the establishment of weld acceptance codes ${ }^{16}$. In this context, the present work evaluates the use of ultrasonic phased array technique to detect defects present in laser beam welded thin AA6013 sheets, mainly those related to porosity. X-ray radiography and metallographic examination are also used to support the results obtained by ultrasonic inspection. 


\section{Experimental Setup}

Autogenously bead on plate welds were performed on the alloy AA6013-T4 (Al-Mg-Si-Cu), $1.6 \mathrm{~mm}$ thick sheets. A high power Yb-fiber laser (IPG, model YLR 2000S) with a $2 \mathrm{~kW}$ maximum power was used in the experiments. The process fiber was $10 \mathrm{~m}$ long, with a diameter of $100 \mu \mathrm{m}$. The focal spot diameter obtained on the top surface of the work piece was $100 \mu \mathrm{m}$. The welds were performed with a $1.5 \mathrm{~kW}$ power beam travelling over the aluminum surface at a speed of $6 \mathrm{~m} / \mathrm{min}$. Both high and low porosity welds were produced, in order to assess the NDI detection ability. Protective gas (He $40 \mathrm{~L} / \mathrm{min}$ flow rate) was used to produce low porosity welds, while the high porosity welds were obtained removing the protective gas.

The welded sheets were submitted to radiographic inspection, using an industrial X-Ray Equipment ERESCO MF3 Series, 200 kV power and current of 4,5 mA. The sheets were also submitted to ultrasonic phased array inspection, using Omniscan MX R/D Tech Technology equipment with a Panametrics 10L32 A1 sensor (frequency of $10 \mathrm{MHz}$ ), containing 32 piezoelectric elements switched in groups of 16 consecutive elements ( 1 to 17,2 to $18 \ldots . .17$ to 32 ), emitting simultaneously waves in phase. Longitudinal waves were employed, with a gain of $18,8 \mathrm{~dB}$. A focus depth of $10 \mathrm{~mm}$, higher than the sheet thickness, was employed in order to guarantee that sound waves (both pulse and echo) propagate parallel each other through the sample thickness. The welds were inspected from the top side (beam incident side), that was smoothed by slight sanding in order to obtain a proper coupling with the sensor. Methyl-cellulose based solution was used as a coupling media. Figure 1 illustrates the acquisition procedure. The $70 \mathrm{~mm}$ welding line was divided in 10 parts and the $7 \mathrm{~mm}$ length probe was positioned over each part, remaining stationary during acquisition. Consequently 10 acquisitions covered $100 \%$ of each welding line. Both A and B-scan modes were recorded. The B-scan image corresponds to the integral of the pulse/ echo records from sets of switched elements of the probe. The A-scan readings correspond to the intensity of the echo relative to the pulse (percentage from the pulse intensity) and are obtained for a specific set

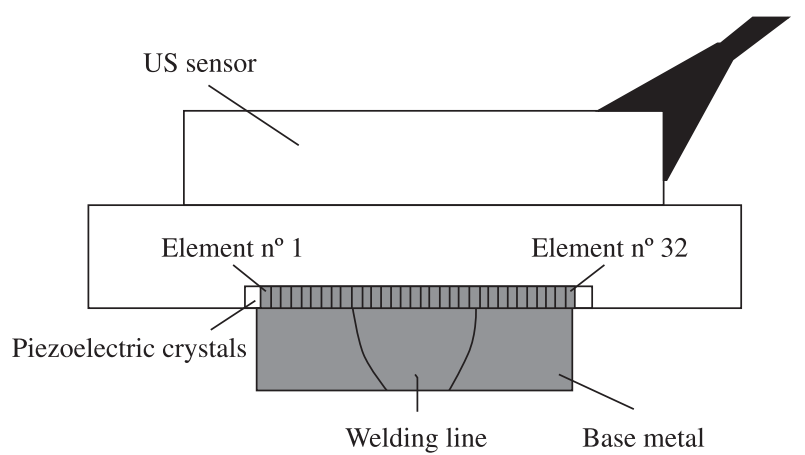

(a)

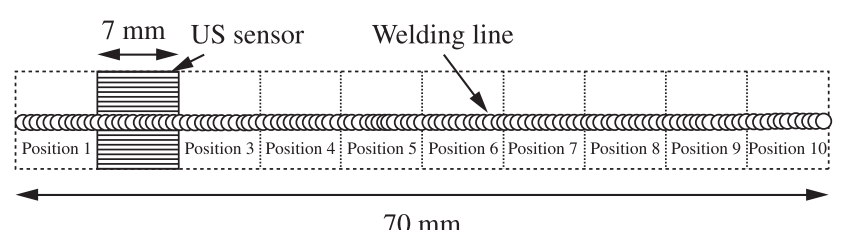

$70 \mathrm{~mm}$

(b)

Figure 1. Setup for ultrasonic inspection: a) perpendicular alignment of the 32 piezoelectric elements related to the welding line; and $b$ ) transducer position over the welding line, repeated 10 times to cover the entire weld length. of switched elements directly from the equipment. After the NDIs, the samples were cut and prepared for metallographic examination using conventional grinding, sanding, polishing and etching operations, in order to have a direct visualization of the welding defects. Optical and Scanning Electron Microscopy were employed to characterize the microstructure of the welds.

\section{Results and Discussion}

\subsection{Non destructive inspection}

Radiographic images of welding lines in both, high and low porosity samples are presented in Figure 2. Positions 1 to

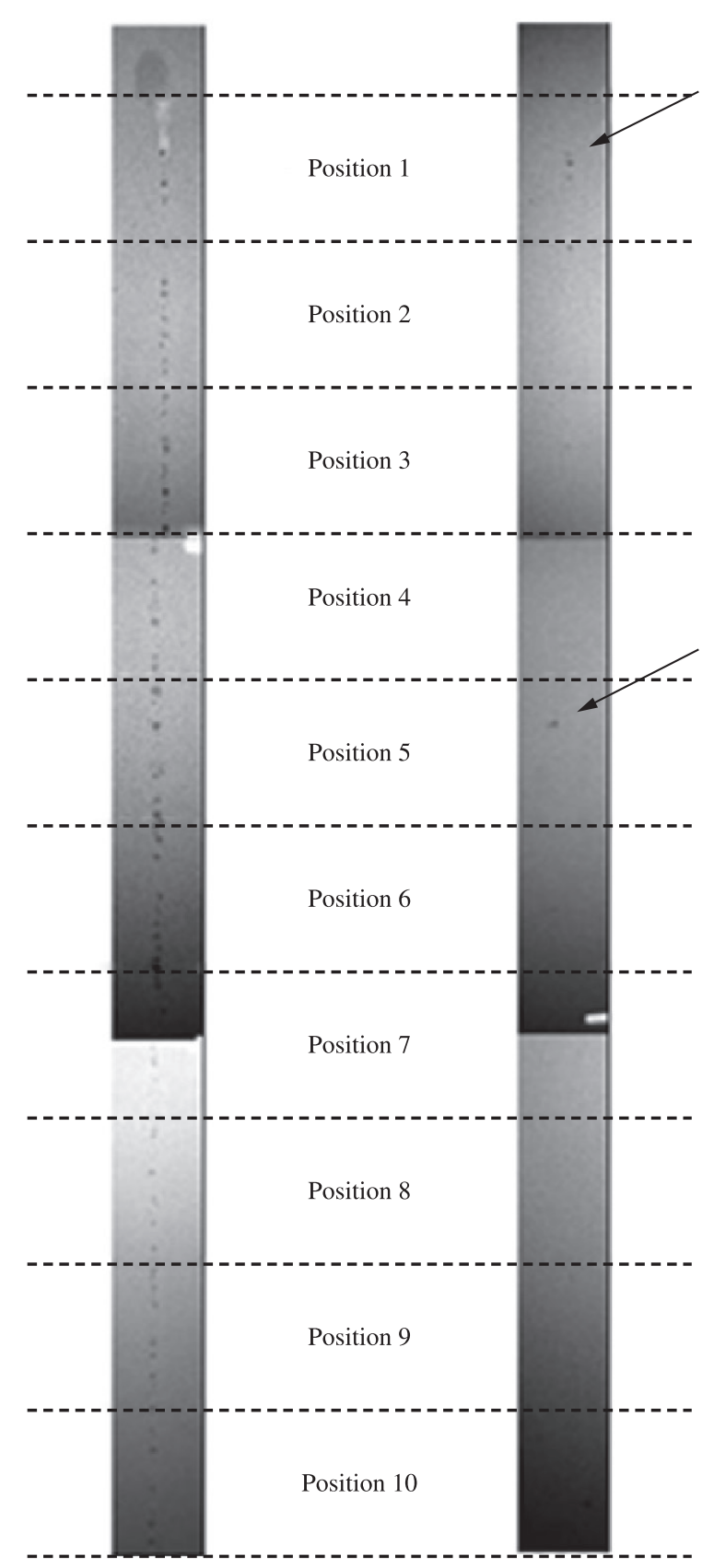

Figure 2. Radiographic images obtained for both high (a) and low (b) porosity welds, with isolated pores marked by arrows. The later weld was performed under a $40 \mathrm{~L} / \mathrm{min}$ flow rate He protective gas. 


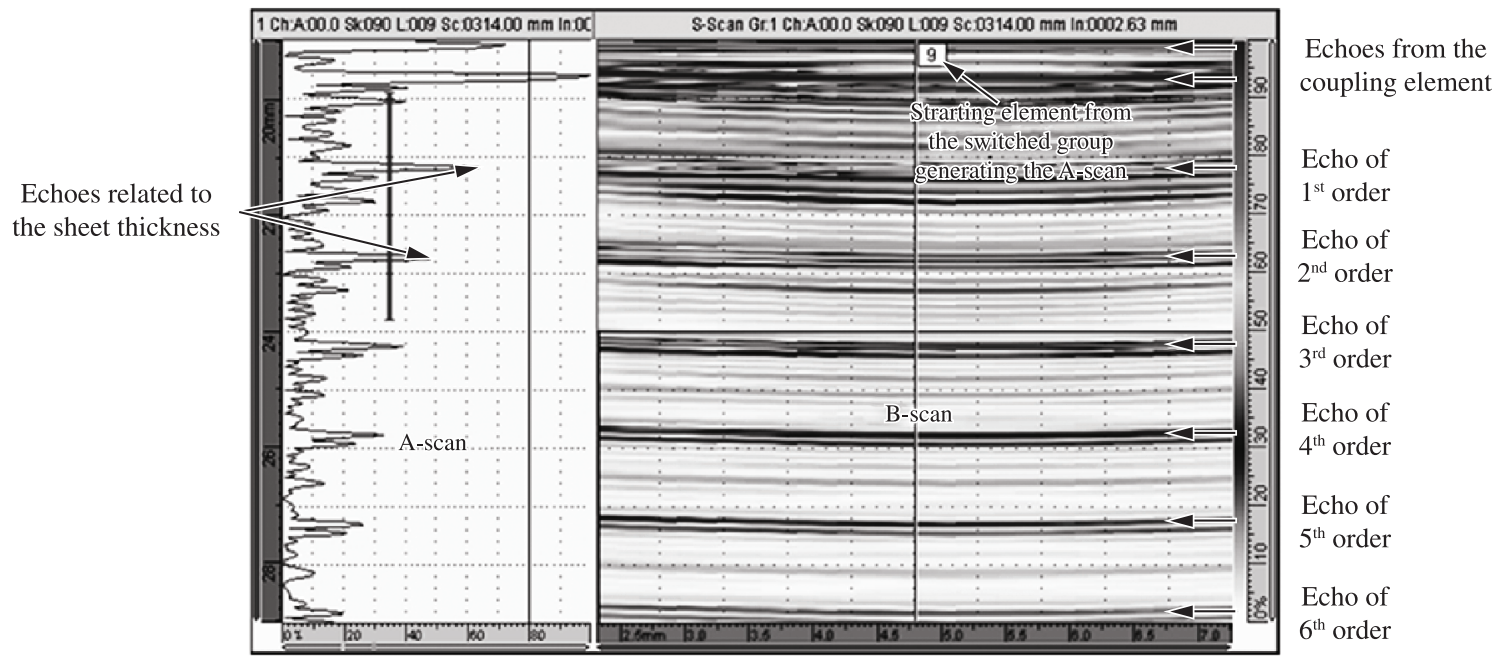

Figure 3. Results of ultrasonic inspection in the sample containing low density of pores. This acquisition corresponds to the position 1 of the welding line, according to Figure 2. The A-scan is in the left side and corresponds to the signal of the 16 switched elements starting with the element 9 , positioned over the welding line. The B-scan image is in the right.

10 corresponds to the probe position related to the welding length (Figure 1b). The use of protective gas plays an important role on pores prevention, as shown in Figure 2. Only few isolated pores are observed in the samples welded using protective gas, mainly at the welding starting point, where the beam usually is not stabilized, Figure $2 \mathrm{~b}$. Contrasting with this aspect, the Figure 2 a shows a high concentration of large pores homogeneously distributed from positions 1 to 6 . From positions 7 to 10 , the pores concentration is smaller.

The image obtained from the ultrasonic phased array inspection of the sample with low density of pores is shown in Figure 3. B-scan image is seen at the right and corresponds to the position 1 of the welding line (refer to Figures $1 \mathrm{~b}$ and 2). The A-scan image is seen in the left and in this case corresponds to a switching between elements 9 to 24 (most of them positioned over the weld), as observed by the vertical line named " 9 " over the B-scan image. It is worth mentioning that the best signal to noise ratio was obtained using 16 switched elements. The amplitude of the signal decreases as the number of switched sensors decreases, although the lateral resolution could be improved.

Grouped horizontal lines in B-scan represent multiple reflections, as the sound waves are successively reflected and attenuated on the upper and bottom surfaces of the sample. The same effect is observed in A-scan image, in the form of periodic intensity peaks. The intensity of the echoes decreases as the number or order of reflection increases. Echoes from the coupling element are also seen in both B-scan and A-scan images. It can be observed from this figure that no indication of pores is observed in B-scan, although an isolated pore is seen in radiographic inspection (Figure 2). The same was observed in the B-scan acquisition with the probe positioned in the region 5, which also contain an isolated pore.

The Figure 4 shows the B-scan image obtained in the position 3 of the weld containing high density of pores. It is evident that considerable attenuation occurs in the middle of the B-scan image (corresponding to the welding line position) for all of the back reflected signals, represented by the whitening of the horizontal lines. This result corresponds to the reduced transmissibility of the material in presence of pores, which scatters the sound waves, and is essentially qualitative. It can also be observed from Figure 4 that the width of the whitening region increases for reflections of higher

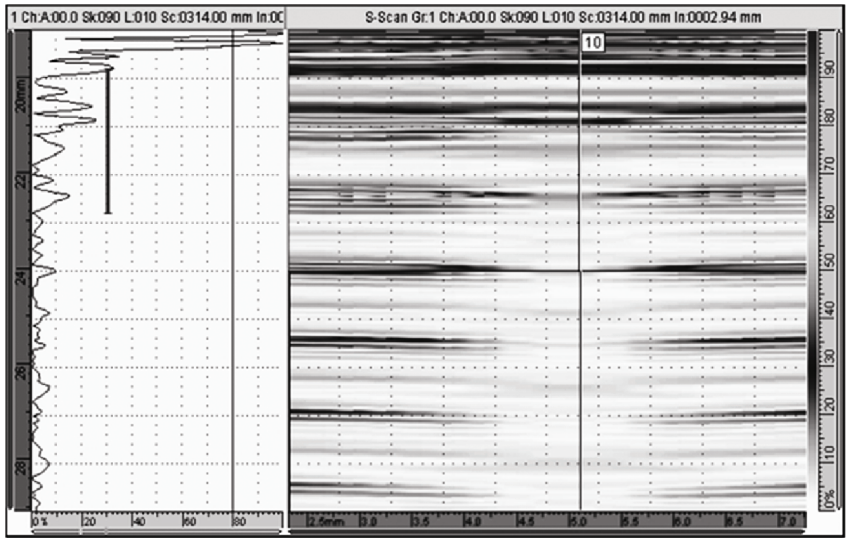

Figure 4. Results of ultrasonic inspection from the sample containing high porosity level. This acquisition corresponds to the position 3 of the welding line, according to Figure 2. The A-scan is in the left side and corresponds to the signal of the 16 switched elements starting with the element 10 , positioned over the welding line. The B-scan image is in the right.

order, indicating that the scatter effect of the pores increases with the reflection order.

In order to have a quantitative value for the attenuation, A-scan spectra from different switched groups of elements were evaluated. The intensity of the first pulse and the first reflection (echo) was measured for elements from the probe located over the base-metal and over the welding line. When the attenuation obtained from A-scan is plotted as a function of the element position (base metal or welding bead), interesting information can be obtained. Figure 5 shows the intensity of the first echo from the A-scan for both base metal and welding line. In 5 a the sample corresponds to the low porosity weld, with four groups of switched elements collecting signal mostly from the base-metal and three groups mostly from the welding line. It can be observed that, even in the absence of defects, the welding line scatters the sound, decreasing the echo intensity. The average intensity values from base-metal and welding line ranges from 56 to $67 \%$ and 40 to $61 \%$ from the initial pulse, respectively. The difference in attenuation between the base metal and the low 


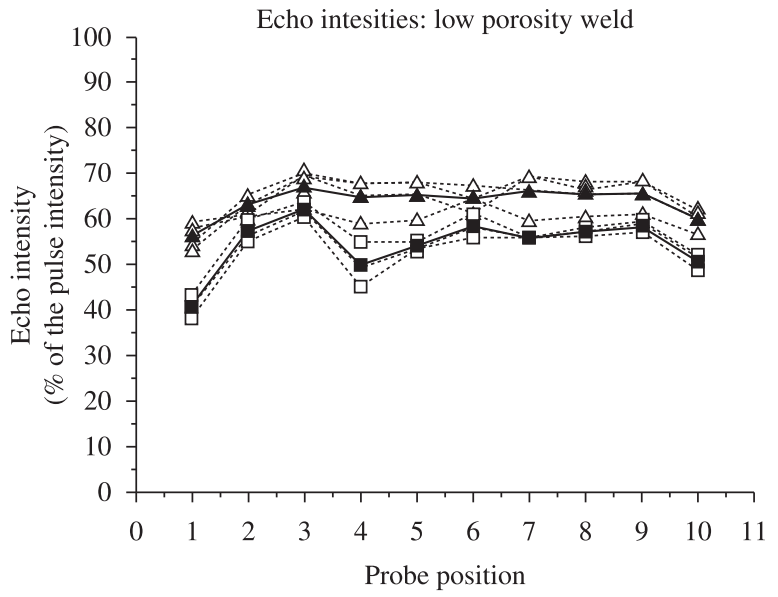

(a)

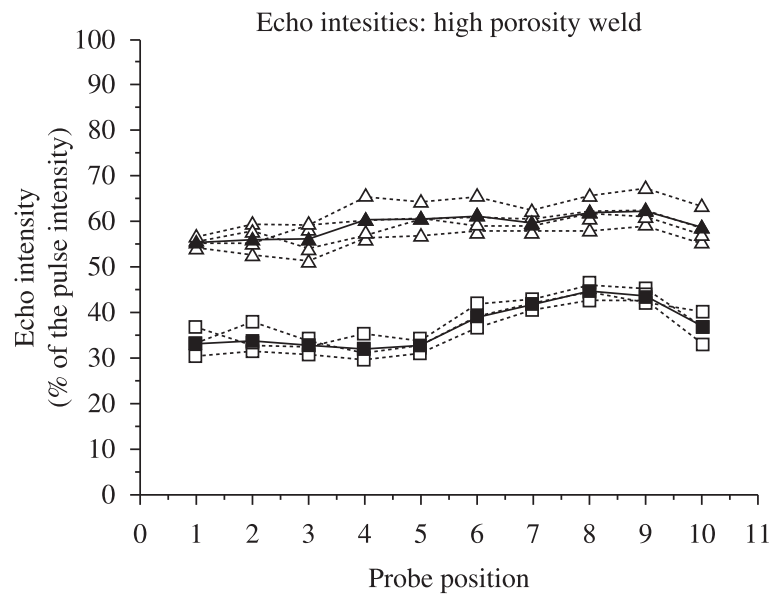

(b)

$\therefore \Delta$ - Base metal $\_$Base metal mean value $\quad-\square-$ Welding line $\rightarrow-$ Welding line mean value

Figure 5. Relative intensity of first echo in percentage of the initial pulse for both base metal and welding line: a) sample with low porosity level; and b) sample containing high porosity level. For the base metal values, signals of four groups of elements are plotted, two in the left and two in the right side of the bead. For weld bead values, signals of groups of three elements are plotted. Darker lines correspond to average curves.

porosity weld in this case ranges from 5 to $15 \%$ and can be related to the difference in the microstructure, resulted from the melting. This difference tends to be higher in regions containing isolated pores, like regions 1 and 5 (Figure 2). In fact, when comparing the Figures $2 \mathrm{~b}$ and $5 \mathrm{a}$, a small difference related to an isolated pore position is observed. In $2 b$ the pore is in the position 5 while in $5 \mathrm{a}$ a significant attenuation is observed in position 4 . This difference can be related to an experimental error during the probe positioning, as the distance of the pore in Figure $2 b$ is only $2 \mathrm{~mm}$ far from the transition between positions 4 and 5 . The attenuation in the signal of elements positioned over the welding line is more significant in presence of high porosity level, Figure $5 \mathrm{~b}$. In this case, the intensity of the first echo ranges from 32 to $44 \%$ of the initial pulse, when comparing to the range of 40 to $61 \%$ from the low porosity weld. The net difference between the base metal and welding line in this case ranged from 17 to $28 \%$. Similar results were obtained for laser welded $\mathrm{C} 45$ steel $^{17}$, where micro cracks resulted from high sulfur content could be identified through the increase in the pulse/echo ultrasonic attenuation. Differences in A-scan readings from sound and defective welds were also successfully processed by neural networks, to access the welding quality ${ }^{13}$. On the other hand, B-scan images were able to detect tight void defects in FSW joints ${ }^{18}$ indicating that the inspection conditions could be optimized if the objective is to have a direct visualization of the defects.

Although the attenuation on the base metal itself can vary significantly ( 52 to $70 \%$ for both samples), depending on the coupling conditions, this range is clearly distinct from the attenuation range of the welding line, even with low porosity level. This is evident when comparing the normalized values in Figure 6. It can be observed that for the low porosity welds, the amplitude of echoes remains between 80 and $95 \%$ of the amplitude of the base metal (excluding the two points at probe positions 1 and 4, related to isolated pores), while for high porosity welds it remains between 55 and $75 \%$. Moreover, the comparison of Figures $2 \mathrm{a}$ and 6 shows that in the region where the pores concentration is smaller (positions 7 to 10) the echo amplitude tends to increase. Based in this result, it seems that this method is sensitive to small variations in pores density. Consequently it seems to be feasible to obtain typical attenuation values for acceptable

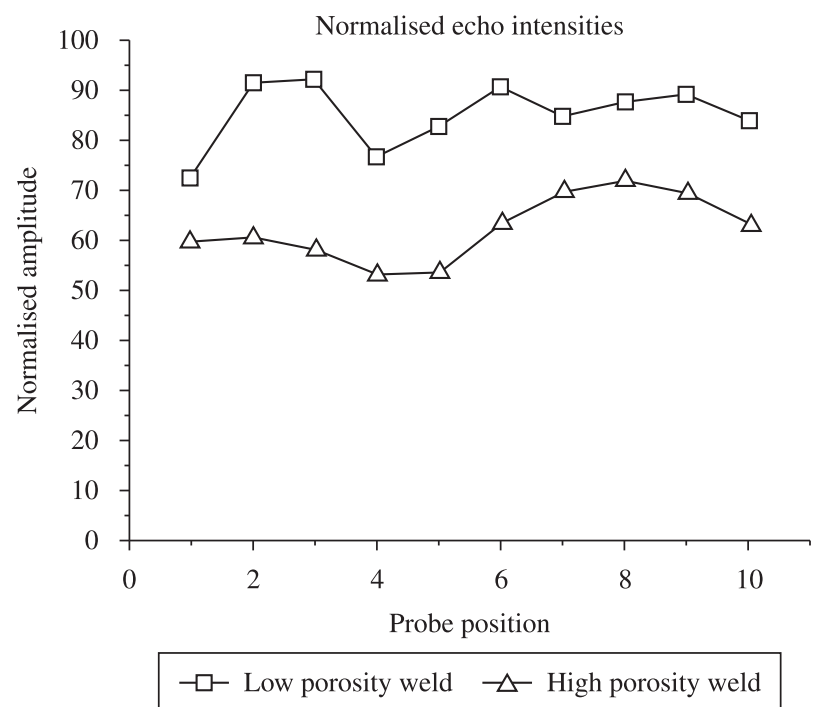

Figure 6. Normalized amplitude of echoes for low and high porosity welds.

porosity levels, based on weld acceptance $\operatorname{codes}^{16}$. Once these levels are established, it is possible to employ the pulse/echo phased-array ultrasonic inspection as a tool for quality control of laser beam welds.

\subsection{Microstructural evaluation of the welds}

The Figure 7 shows the microstructure of the welding line, obtained in a cross section of the sample with high porosity level, perpendicular to the welding line. The chemical etching reveals a fine microstructure obtained in the fusion zone, where several pores ranging from about 30 up to $200 \mu \mathrm{m}$ are present. It can also be observed a small region at the bottom of the image revealing a transition between fusion zone and heat affected zone, containing higher elongated grains. Figure 8 shows a cross section of the welding line, showing a typical full penetration "V" shape weld. In Figure 8a, a region containing a unique small isolated pore is seen. It is also 


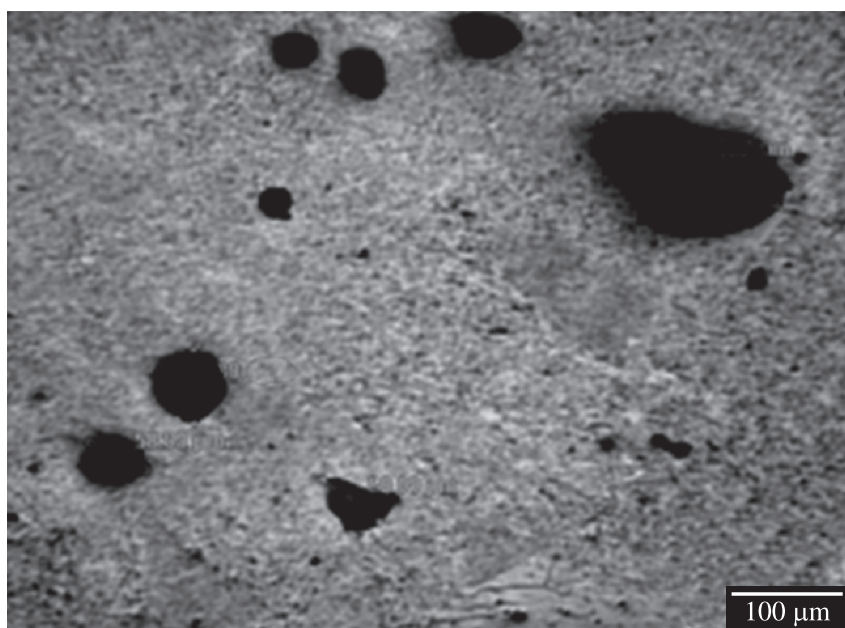

Figure 7. Microstructure of the cross section of the sample containing high porosity. Pores diameter ranges from 30 to $200 \mu \mathrm{m}$. This section was taken longitudinally to the welding line. Chemical etching was performed using Keller's reagent. observed that a very narrow (about $20 \mu \mathrm{m}$ wide) heat affected zone exists between the central melted zone and the base-metal. Further, a number of insoluble precipitates, typical of the commercial alloy, are seen in the base metal as small dark spots. In $8 \mathrm{~b}$ is shown a very big pore (about $300 \mu \mathrm{m}$ wide) co-existing with two others of smaller size (about $30 \mu \mathrm{m}$ wide). Such large pores were very common on the sample welded without protective gas, as observed in Figure 2a.

Figure 9 presents scanning electron micrographs obtained for the sample with low porosity level. Back-scattering electrons contrast in Figure 9a reveals that the transition between fusion zone (top of the image) and the base-metal is very sharp, characterized by a remarkable transition in the grain size. Dark spots visible in the base metal are related to voids left by precipitates removal after metallographic/etching sample preparation. A region containing wider grain boundaries is observed, extending about $20 \mu \mathrm{m}$ from the fusion zone. This region makes the transition between melted and basemetal regions, and is the visible part of the heat affected zone. The grain boundary widening is a result of the metallographic chemical etching, which is enhanced in regions with eutectic microstructure. This leads to the conclusion that these grain boundaries were partially

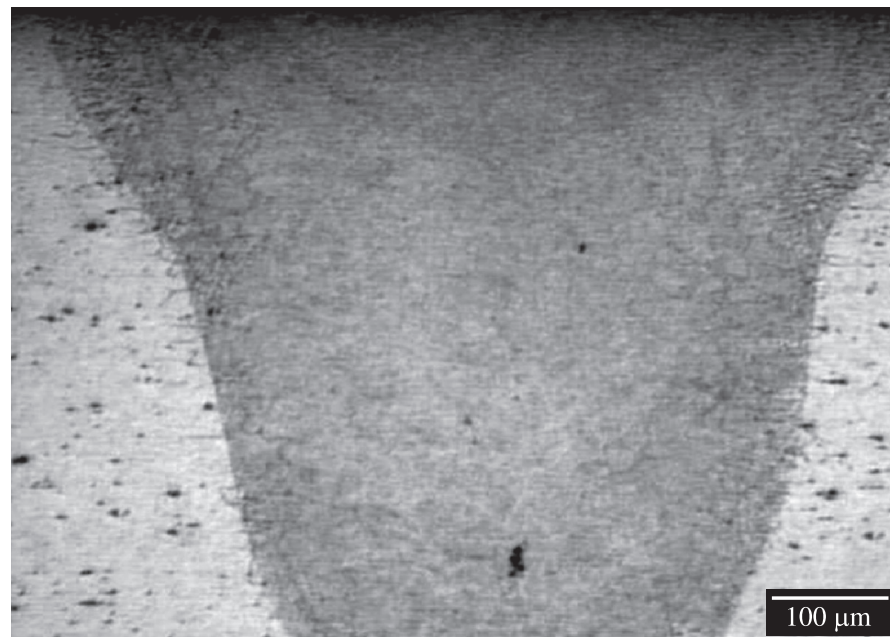

(a)

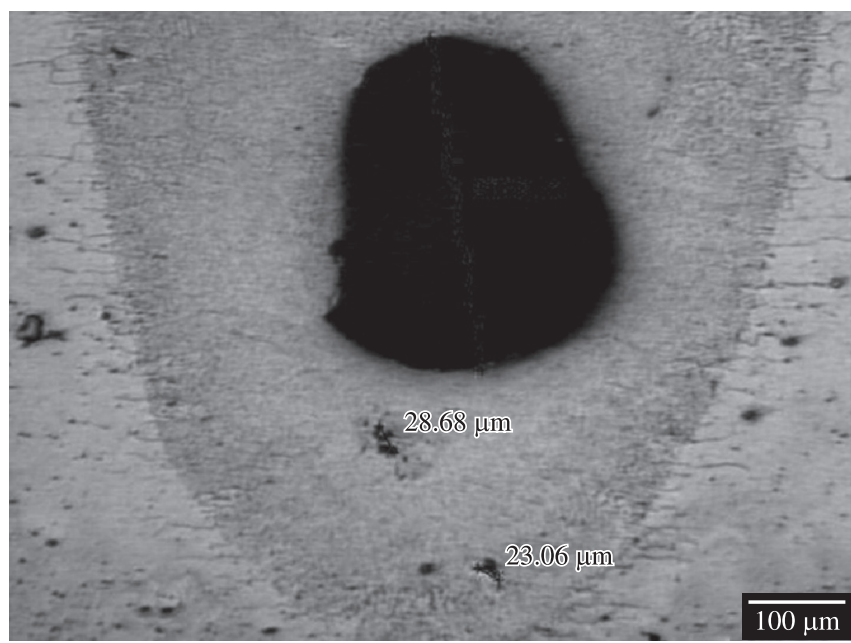

(b)

Figure 8. Microstructure of the sample, perpendicular to the welding direction, containing high porosity: a) region containing only small pores; and b) region containing a big pore $(300 \mu \mathrm{m}$ in diameter), co-existing with other small pores (about $30 \mu \mathrm{m}$ in diameter). No chemical etching.

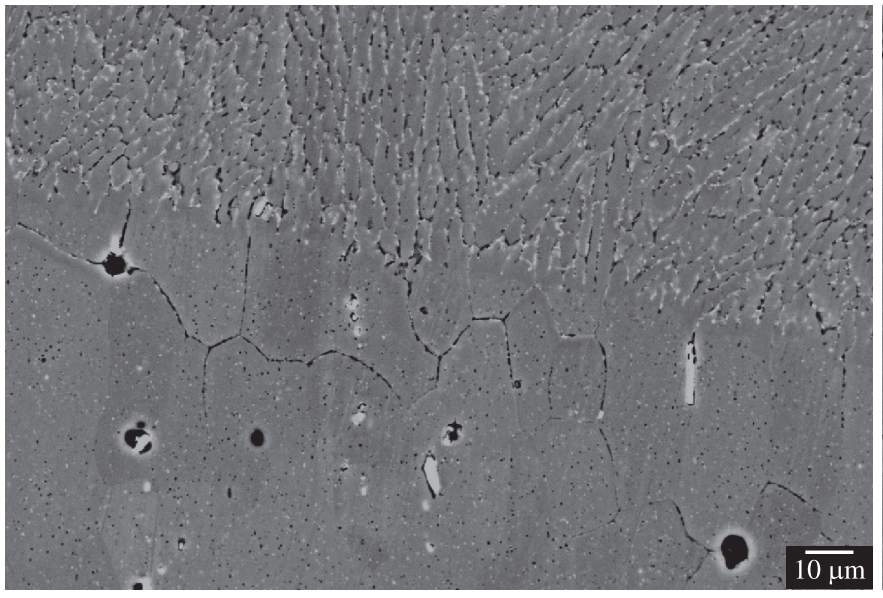

(a)

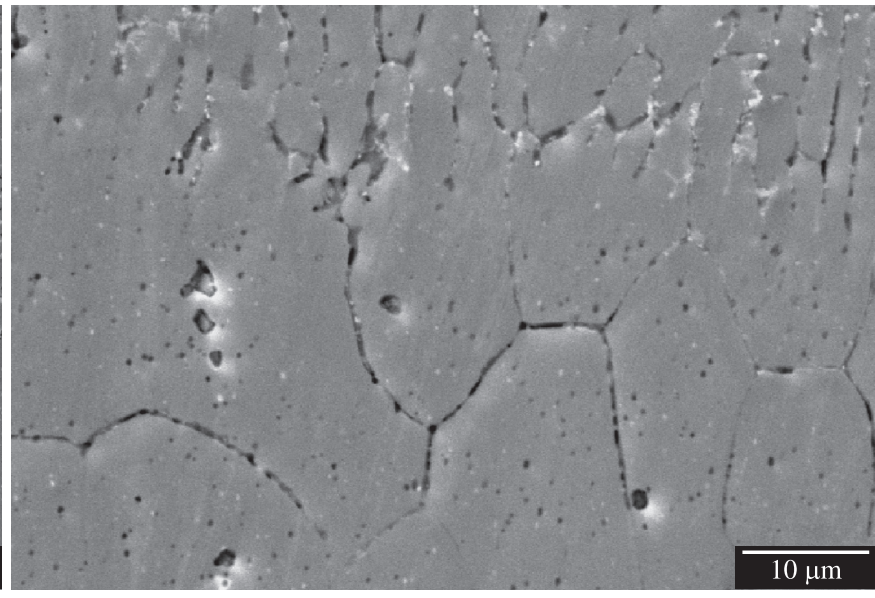

(b)

Figure 9. Scanning electron micrographs obtained from the low porosity welding: a) overall view using a back scattering electron contrast; and b) detail of (a), using secondary electrons. Keller's etching reagent. 
melted during the welding. In Figure 9b, a higher magnification of this region shows that the welds are free of cracks.

Intensive evaluation was performed through metallographic inspection on several sections of the welding lines and no discontinuities, other than porosity, were verified. The welded samples were free from cracks and consequently it was not possible to evaluate the potential of the ultrasonic inspection in detecting such planar defects. The biggest pore found on samples had a diameter of about $300 \mu \mathrm{m}$. As the frequency "f" of the probe used was $10 \mathrm{MHz}$ and considering that the sound velocity in aluminium " $\mathrm{V}$ " is about $6300 \mathrm{~m} / \mathrm{s}$, the wavelength " $\lambda$ " inside the sample can be calculated as $630 \mu \mathrm{m}(\mathrm{V}=\lambda \mathrm{xf})$, which is about double of the pores diameter. This could explain the fail in detecting isolated pores in B-scan. Further, the use of 16 switched elements seems to decrease the lateral resolution. It is worth mentioning that dealing with such narrow welds (about $1,0 \mathrm{~mm}$ wide) in thin sheets, it seems to be not practical to have a direct visualization of the pores in B-scan mode. Instead, it seems to be more productive to increase the signal to noise ratio and distinguish a sound from a porous weld by the level of the signal scattering, establishing a maximum level permitted based on microestructural and mechanical tests associated with each porosity level.

\section{Conclusion}

Ultrasonic phased array inspection has been investigated for the detection of defects in thin aluminum laser beam welded sheets. A correlation between this technique and radiographic and metallographic inspections has been performed. From the results obtained in this work, the following conclusions can be drawn:

- the absence of protective gas during welding lead to a high porosity weld;

- direct observation of the pores in the B-scan mode was not possible in the present work. Higher frequency probes could improve the inspection detection limit. Most of these pores were easily identified by radiographic inspection;

- when the attenuation of the ultrasonic waves was obtained separately for base metal, low porosity weld and high porosity weld (through A-scan spectrum), it was easily possible to identify not only the welding line, but also the presence of grouped pores. This principle can be applied to "in process" porosity control of laser welded sheets, since no contacting techniques are employed;

- setting the focus depth of the equipment very far from the thickness of the sheet and switching a large number of elements, emitting and receiving simultaneously the signal, seems to improve the parallelism of the waves from different piezoelectric sensors and increase the signal to noise ratio. Consequently, the presence of pores could be indirectly identified in the narrow laser welding line; and

- as no micro-cracks were found by metallographic inspection on the welded samples, it was not possible to verify if the principle of ultrasonic waves attenuation can be applied to cracks detection in the welding line.

\section{References}

1. Braun R. Nd:YAG laser butt welding of AA6013 using silicon and magnesium containing filler powders. Materials Science and Engineering A. 2006; 426:250-262. http://dx.doi.org/10.1016/j.msea.2006.04.033

2. Pacchione M and Telgkamp J. Challenges of the Metallic Fuselage. In: Proceedings of the 25th International Congress of the Aeronautical
Sciences - ICAS; 2006; Hamburg, Germany. Optimage Ltd.; 2006. p. 451.1-4.5.1.12.

3. Lenczowski B. New lightweight alloys for welded aircraft structure. In: Proceedings of the 23th International Congress of the Aeronautical Sciences - ICAS; 2002; Totonto, Canada. Optimage Ltd.; 2002. p. 4101.1-4101.4.

4. Ditchburn RJ, Burke SK and Scala CM. NDT of welds: state of the art. NDT \& E International. 1996; 29(2):111-117. http://dx.doi. org/10.1016/0963-8695(96)00010-2

5. Olympus Inspection \& Maintenace Systems. Ultrasonic Phased Array. Available from: $<$ http://www.olympus-ims.com/en/ndt-tutorials/phasedarray/>. Access in: 12/01/2011.

6. Arone M, Cerniglia D and Nigrelli V. Defect characterization in Al welded joints by non-contact Lamb wave technique. Journal of Materials Processing Technology. 2006; 176:95-101. http://dx.doi.org/10.1016/j. jmatprotec.2006.02.024

7. Green Junior RE. Non-contact ultrasonic techniques. Ultrasonics. 2004; 42:9-16. http://dx.doi.org/10.1016/j.ultras.2004.01.101

8. Lee J-R, Jeong H, Ciang CC, Yoon D-J and Lee S-S. Application of ultrasonic wave propagation imaging method to automatic damage visualization of nuclear power plant pipeline. Nuclear Engineering and Design. 2010; 240:3513-3520. http://dx.doi.org/10.1016/j. nucengdes.2010.06.011

9. Staszewski WJ, Lee BC and Traynor R. Fatigue crack detection in metallic structures with Lamb waves and 3D laser vibrometry. Measurement Science and Technology. 2007; 18:727-739. http://dx.doi. org/10.1088/0957-0233/18/3/024

10. Tabatabaeipour SM and Honarvar F. A comparative evaluation of ultrasonic testing of AISI 316L welds made by shielded metal arc welding and gas tungsten arc welding processes. Journal of Materials Processing Technology. 2010; 210:1043-1050. http://dx.doi.org/10.1016/j. jmatprotec.2010.02.013

11. Hatsukade Y, Takahashi T, Yasui T, Tsubaki M, Fukumono M and Tanaka S. Study on nondestructive inspection using HTS-SQUID for friction stir welding between dissimilar metals. Physica C. 2007; 463-465:1038-1042. http://dx.doi.org/10.1016/j.physc.2007.01.072

12. Tsukada K, Yoshioka M, Kiwa T and Hirano Y. A magnetic flux leakage method using a magneto resistive sensor for non destructive evaluation of spot welds. NDT\&E International. 2011; 44:101-105. http://dx.doi. org/10.1016/j.ndteint.2010.09.012

13. Martín O, López M and Martín F. Artificial neural networks for quality control by ultrasonic testing in resistance spot welding. Journal of Materials Processing Technology. 2007; 183:226-233. http://dx.doi. org/10.1016/j.jmatprotec.2006.10.011

14. Chen Z, Shi Y, Jiao B and Zhao H. Ultrasonic nondestructive evaluation of spot welds for zinc-coated high strength steel sheet based on wavelet packet analysis. Journal of Materials Processing Technology. 2009; 209:2329-2337. http://dx.doi.org/10.1016/j.jmatprotec.2008.05.030

15. Vieira AP, De Moura EP, Gonçalves LL and Rebello JMA. Characterization of welding defects by fractal analysis of ultrasonic signals. Chaos, Solitons and Fractals. 2008; 38:748-754. http://dx.doi.org/10.1016/j. chaos.2007.01.012

16. American Welding Society - AWS. AWS D17.1:2001: Specification for fusion welding for aerospace applications. AWS; 2001.

17. Göbel G and Brenner B. New thermo-mechanical approach to overcome hot cracking in laser welding. In: Proceedings of the Fourth International WLT-Conference on Lasers in Manufacturing; 2007; Munich, Germany. Munich; 2007.

18. Li B, Shen Y and Hu W. The study on defects in aluminum 2219-T6 thick butt friction stir welds with the application of multiple non-destructive testing methods. Materials and Design. 2011;32:2073-2084. http://dx.doi. org/10.1016/j.matdes.2010.11.054 